\title{
LA CIUDAD FALLIDA
}

Juan Miguel Morell y Fuentes (Arquitecto - Profesor asociado DUyOT)

Uno de los temas que han surgido en estos años y que serán objeto de multitud de disquisiciones en este siglo, han sido las ampliaciones fallidas de ciudades.

Con mayor o menor intensidad, con mayor o menor desarrollo en multitud de poblaciones, se han producido ocupaciones de suelo con urbanizaciones, pavimentaciones, estructuras incompletas y toda suerte de elementos constructivos, que han modificado suelo, paisaje y las economías municipales y de los ciudadanos. Los planteamientos especulativos en todos los órdenes, propiedad del suelo, gestión, urbanizadores, promotores, constructores, técnicos.... han llevado a planificar desarrollos ilusorios de crecimiento de las poblaciones, bien por incrementos poblacionales que superaban valores imposibles, bien por futuros industriales que iban a eclipsar los de poblaciones vecinas, bien por una riqueza que iba a alcanzar para todo.

Al final, todas las expectativas chocaron con la realidad y la economía y, tras los oportunos esfuerzos de toda índole ha acabado en agua de borrajas y han llevado a los municipios a un fracaso en sus pretensiones de ampliación. Uno de los casos que, por haber visto su desarrollo y la situación que actualmente presenta, es el de la ciudad de Mérida, capital administrativa de Extremadura.

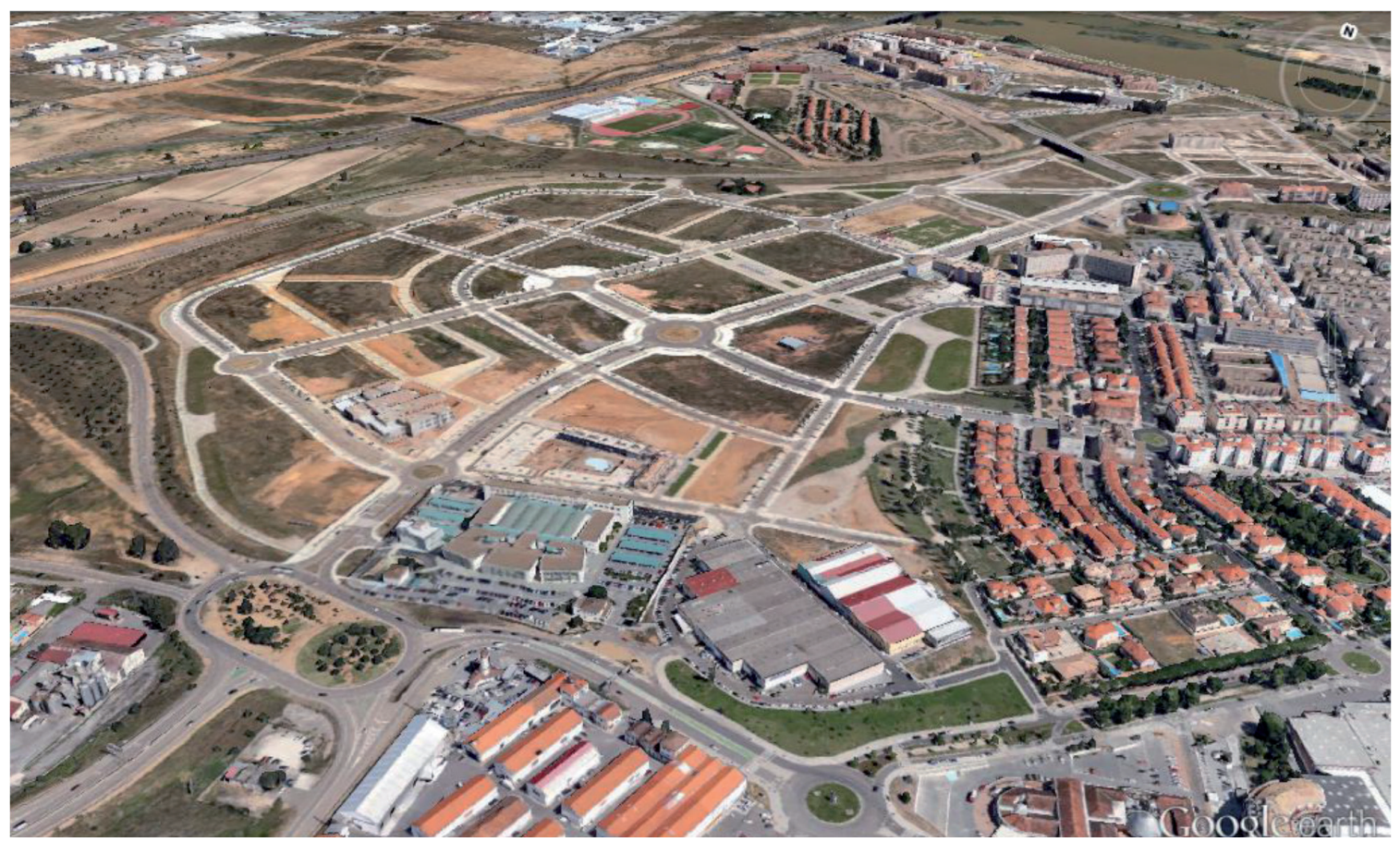

Figura 2. Estado actual de los nuevos ensanches urbanos en la ciudad de Mérida (España)

Fuente: Google Earth 
No voy a hacer una historia de su desarrollo, pero sí señalar lo ocurrido en los últimos diez años. Desde que se formó su nombramiento como sede del Gobierno Autónomo, las expectativas de crecimiento tuvieron su fundamento y se acomodaron a esta realidad, pero, una vez alcanzado el nivel que semejante titularidad podría generar, los desarrollos fueron desproporcionados al tamaño que se podría lograr. Hectáreas de suelo, con un valor natural de más o menos valía agrícola, medioambientalmente propicios como entorno de la ciudad, han sido "adecuados" al desarrollo urbano, moviendo tierras, pavimentando, organizando redes de desagües, eléctricas y todo lo preciso para que pudieran ocuparse (construirse) las parcelas resultantes.

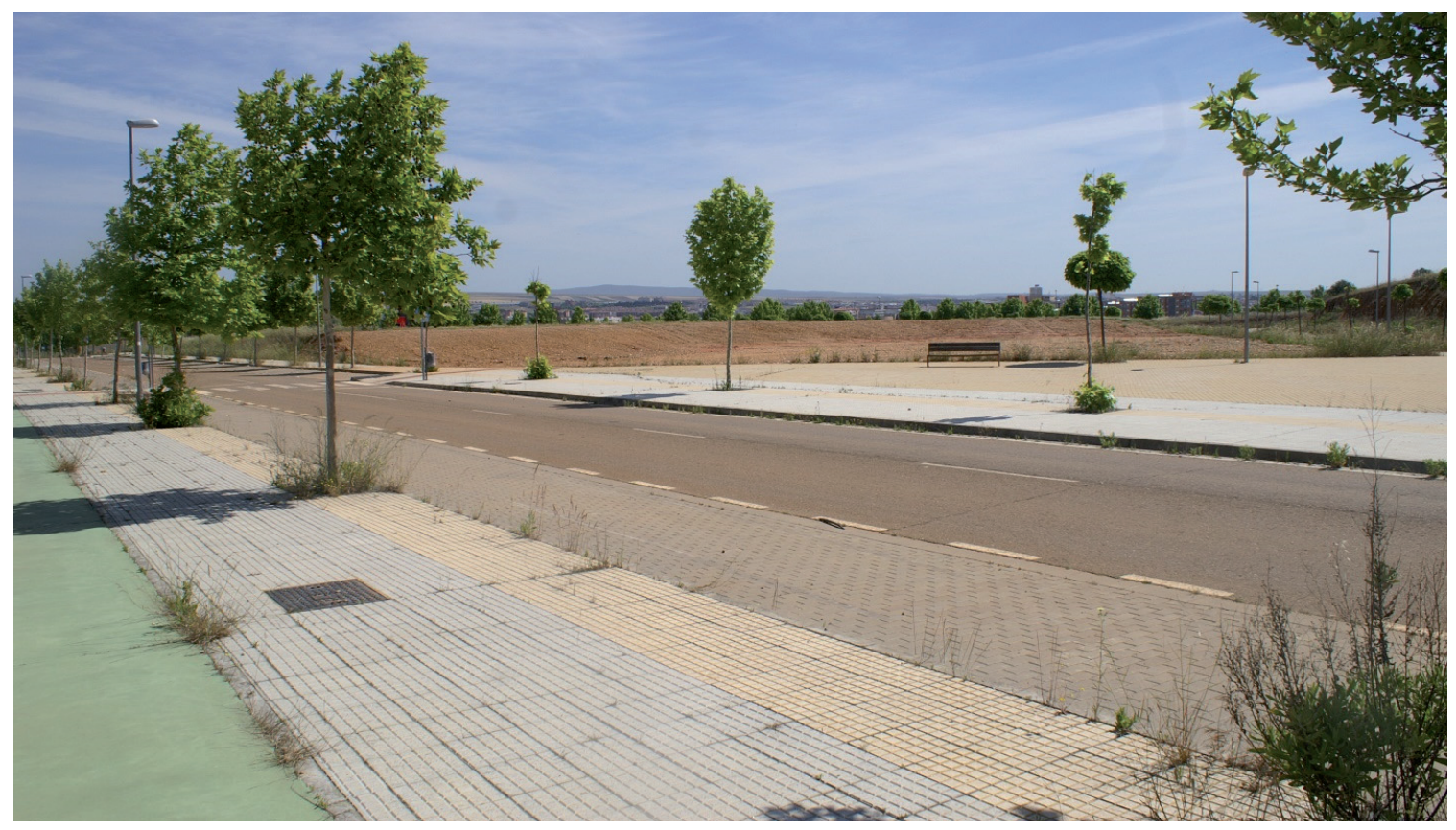

Figura 3. Vista de una de las calles de los nuevos ensanches urbanos en la ciudad de Mérida (España) Fuente: Archivo del autor

Pero las escasas intervenciones (algunas viviendas VPO, centros médicos y estructuras en "stand by") no han llegado a ocupar un $5 \%$ de todo lo modificado. Las impolutas calles, con sus carriles bici-acerados, arbolados, alumbrados, mobiliario urbano, sólo sirven para atajar la comunicación entre áreas de la ciudad (algunas de ellas) y, el resto, para paseo esporádicos de practicantes de footing y cientos de ciempiés, sus usuarios casi exclusivos al haberles "robado" parte de su hábitat; son los dueños materiales de este espacio. Los recintos para construcción (solares) son la manifestación de los movimientos de tierras, acumuladores de residuos y la degradación del suelo natural, toda una exhibición tras la simple torsión. Las zonas pavimentadas, fruto de una ejecución cuidada, soportan honrosamente el abandono de su futuro que ha hecho que carezcan del mantenimiento propio, al no ser generadoras de recursos. Las redes de alumbrado y sus equipos, el riego, arquetas y mobiliario, poco a poco se "vampirizan" y, en este vacío, sólo destacan las instalaciones infantiles que languidecen, esperando a unos usuarios que tardarán muchos años en disfrutarlas. 